\title{
Cell cycle control of telomere protection and NHEJ revealed by a ts mutation in the DNA-binding domain of TRF2
}

\author{
Akimitsu Konishi ${ }^{1}$ and Titia de Lange ${ }^{2}$ \\ Laboratory for Cell Biology and Genetics, The Rockefeller University, New York, New York 10065, USA
}

\begin{abstract}
TRF2 is a component of shelterin, the telomere-specific protein complex that prevents DNA damage signaling and inappropriate repair at the natural ends of mammalian chromosomes. We describe a temperature-sensitive (ts) mutation in the Myb/SANT DNA-binding domain of TRF2 that allows controlled and reversible telomere deprotection. At $32^{\circ} \mathrm{C}$, TRF2ts was functional and rescued the lethality of TRF2 deletion from conditional TRF2 $^{\mathrm{F} /-}$ mouse embryonic fibroblasts (MEFs). When shifted to the nonpermissive temperature $\left(37^{\circ} \mathrm{C}\right), \mathrm{TRF}^{\mathrm{t}} \mathrm{ts}$ cells showed extensive telomere damage resulting in activation of the ATM kinase and nonhomologous end-joining (NHEJ) of chromosome ends. The inactivation of TRF2ts at $37^{\circ} \mathrm{C}$ was rapid and reversible, permitting induction of short periods $(3-6 \mathrm{~h})$ of telomere dysfunction in the G0, G1, and S/G2 phases of the cell cycle. The results indicate that both the induction of telomere dysfunction and the re-establishment of the protected state can take place throughout interphase. In contrast, the processing of dysfunctional telomeres by NHEJ occurred primarily in G1, being repressed in S/G2 in a cyclin-dependent kinase (CDK)-dependent manner.
\end{abstract}

[Keywords: DNA damage; NHEJ; TRF2; shelterin; telomere]

Supplemental material is available at http://www.genesdev.org.

Received November 14, 2007; revised version accepted March 10, 2008.

TRF1 and TRF2 are closely related telomeric DNA-binding proteins that anchor the other shelterin components (Rap1, TIN2, TPP1, and POT1) to the duplex TTAGGG repeat array of mammalian chromosome ends (Chong et al. 1995; Bilaud et al. 1997; Broccoli et al. 1997; de Lange 2005). Both proteins bind DNA using a C-terminally located Myb/SANT-type DNA-binding domain. Deletion of TRF2 from $\mathrm{TRF}^{\mathrm{F} /-}$ mouse embryonic fibroblasts (MEFs) activates the ATM kinase signaling pathway and results in inappropriate nonhomologous end-joining (NHEJ)-mediated fusion of chromosome ends (Celli and de Lange 2005; Lazzerini Denchi and de Lange 2007). Similar phenotypes are elicited by a dominant-negative allele of TRF2 or with transfection of siRNAs directed to TRF2 (van Steensel et al. 1998; Takai et al. 2003). These methods of TRF2 inhibition are slow (taking $>24 \mathrm{~h}$ ), therefore thwarting attempts to determine the consequences of telomere dysfunction at specific stages of the cell cycle. Furthermore, the current approaches to inactivate TRF2 are not readily reversible. To create a more versatile experimental system, we aimed to generate a

${ }^{1}$ Present address: Medical Top Track (MTT) Program, Medical Research Institute, Tokyo Medical and Dental University, Yushima 1-5-45, Bunkyo-ku, Tokyo 113-8510, Japan.

${ }^{2}$ Correspondending author.

E-MAIL delange@mail.rockefeller.edu; FAX (212) 327-7147.

Article is online at http://www.genesdev.org/cgi/doi/10.1101/gad.1634008. temperature-sensitive (ts) allele of TRF2. Although ts mutants have been instrumental in the analysis of cell cycle transitions and other aspects of the cell biology of fungi, ts alleles have been used only sporadically in mammalian cells, mostly in the context of viral transformation. We argued that the time frame of TRF2 inactivation at the nonpermissive temperature might be short compared with the time mammalian cells spend in G1 and S phase, thus potentially limiting the telomere insult to specific stages in the cell cycle. Here, we present data obtained with a reversible ts allele of TRF2 that leads to rapid telomere failure at the nonpermissive temperature and allows re-establishment of telomere protection at the permissive temperature. The results reveal the effect of cell cycle phase on telomere (dys)function and provide evidence that telomere repair by NHEJ occurs primarily in G1, being repressed in G2 by higher cyclin-dependent kinase (CDK) activity.

\section{Results}

Generation of a ts allele of TRF2

Several considerations focused our attention on the Myb/SANT DNA-binding domain of TRF2 as a target for generating a ts allele. The ability of TRF2 to bind telomeric DNA is essential for telomere protection (van Steensel et al. 1998), the structure of the TRF2 Myb do- 
main is known (Court et al. 2005; Hanaoka et al. 2005; Rhodes 2005), and ts alleles resulting from mutations in the Myb/SANT domains of v-myb and Saccharomyces cerevisiae Rap1 have been documented (Li et al. 1989; Lustig et al. 1990; Kurtz and Shore 1991). Guided by the structural information on the Myb/SANT fold, we generated single amino acid substitutions at 12 positions in the DNA-binding domain of TRF2 (Fig. 1A; Supplemental Table 1). Each mutation was tested in the context of mouse and human TRF2 for its effect on the expression and telomeric localization (Supplemental Table 1). In order to assess the function of the TRF2 variants in the absence of the wild-type protein, they were introduced into p53-deficient $\mathrm{TRF}^{\mathrm{F} /-}$ MEFs /Celli and de Lange 2005) and the endogenous TRF2 was deleted with Cre recombinase. The resulting cell populations, containing only the altered version of human or mouse TRF2 expressed from the introduced cDNA, were tested for their level of telomere protection at different temperatures. The presence of $\gamma \mathrm{H} 2 \mathrm{AX}$ foci at telomeres was used as an index for telomere dysfunction (Fig. 1B; Supplemental Table 1). MEFs containing the wild-type version of TRF2, which served as a control in these experiments, did not show DNA damage foci at telomeres regardless of the incubation temperature. As expected, several mutations appeared to interfere with TRF2 function in a temperature-independent manner, whereas others had no discernable effect on the behavior of TRF2. Three mutations in helix 1 of TRF2 (positions 450, 460, and 462 in human TRF2) resulted in TRF2 variants with slight differences in their ability to protect telomeres at different temperatures. One mutation in helix 2 (I468A) resulted in a mouse TRF2 allele that was fully capable of protecting telomeres at $32^{\circ} \mathrm{C}$ but not at $37^{\circ}$ or $40^{\circ} \mathrm{C}$ (Fig. 1B; Supplemental Table 1). Because of its robust ts behavior, this allele of TRF2 was selected for further study.

\section{Rapid telomere deprotection upon inactivation of TRF2ts}

The I468A allele of mouse TRF2 (hereafter referred to as TRF2ts) was introduced into TRF $2^{\mathrm{F} /-} \mathrm{p} 53^{-/-}$MEFs by retroviral transduction and the endogenous TRF2 allele was deleted from the transduced cells with Cre (Supplemental Fig. 1). A parallel culture, referred to as TRF2wt, was treated the same except that wild-type TRF2 was introduced. Both forms of TRF2 were expressed at significantly higher levels than the endogenous TRF2 (see Fig. 2C; data not shown). At the permissive temperature, the growth rates of the TRF2ts and TRF2wt cells were similar (doubling time 32 and $30.8 \mathrm{~h}$, respectively) (Supplemental Fig. 1B). However, when incubated for 1 or $2 \mathrm{~d}$ at $37^{\circ} \mathrm{C}$ the TRF2ts cells showed a substantial reduction in proliferation and viability (Supplemental Fig. 1C-E), presumably due to telomere deprotection. Telomere deprotection was apparent from the phosphorylation of H2AX and the formation of telomere dysfunction-induced foci (TIFs) (Takai et al. 2003) by $\gamma \mathrm{H} 2 \mathrm{AX}$ and 53BP1 (Fig. 1BD; Supplemental Fig. 2A). The fraction of cells containing $>15 \gamma \mathrm{H} 2 \mathrm{AX}$ TIFs rapidly increased at the nonpermis- sive temperature, reaching the maximal value of $\sim 80 \%$ at $2 \mathrm{~h}$ (Fig. 1C; Supplemental Fig. 2B). The phosphorylated forms of H2AX and ATM were detectable in immunoblots at $1 \mathrm{~h}$ after the temperature shift (Fig. 1D), and phosphorylation of Chk2 was detectable after 6-9 h (Supplemental Fig. 2C,D). When cells were held at $37^{\circ} \mathrm{C}$, the phosphorylated form of Chk2 persisted for several days (Supplemental Fig. 2C) while some of the TIFs disappeared (Supplemental Fig. 2B), presumably due to NHEJ-mediated repair of the deprotected telomeres (see below). As expected, the DNA damage response was largely abrogated in $\mathrm{ATM}^{-/-}$cells (Fig. 1E,F; Supplemental Fig. 2E), consistent with the previously reported role for the ATM kinase in transducing the DNA damage signal resulting from TRF2 loss (Lazzerini Denchi and de Lange 2007). The activation of the ATM kinase pathway at telomeres in TRF2ts but not TRF2wt cells was a telomere-specific effect since both types of cells showed the same response to ionizing radiation (IR) (Supplemental Fig. 2F).

Chromatin immunoprecipitation (ChIP) data confirmed the view that the TRF2ts allele lost telomerebinding activity at $37^{\circ} \mathrm{C}$ (Fig. $\left.2 \mathrm{~A}, \mathrm{~B}\right)$. The recovery of telomeric DNA in ChIPs performed with antibodies to TRF2 or its binding partner Rapl was twofold to threefold lower when cells were incubated at $37^{\circ} \mathrm{C}$. Furthermore, the telomeric association of TIN2, TRF1, and POT1a was significantly reduced at $37^{\circ} \mathrm{C}$ (Fig. 2A,B), even though there was no obvious reduction in the expression levels of shelterin components (Fig. 2C; data not shown). The loss of POT1a may explain the transient phosphorylation of the ATR target, Chk1, which is observed at early time points after the inactivation of TRF2ts (Supplemental Fig. 2B,C; Lazzerini Denchi and de Lange 2007). As these data suggested that TRF2ts evacuated the telomeres at $37^{\circ} \mathrm{C}$, we tested whether this release also occurred in isolated nuclei. Indeed, a substantial fraction of TRF2 as well as both forms of mouse POT1 were released from isolated nuclei upon their incubation at $37^{\circ} \mathrm{C}$ but not at $4^{\circ} \mathrm{C}$ (Fig. 2D). Collectively, the data indicate that the ts allele of TRF2 lacks the ability to maintain its association with telomeric DNA at $37^{\circ} \mathrm{C}$. As a consequence, telomeres have diminished levels of TRF2 and its interacting partners Rap1 and TIN2.

\section{Reversibility of the TRF2ts allele}

TRF2ts protein was relatively stable at $37^{\circ} \mathrm{C}$, remaining detectable in cells incubated for $30 \mathrm{~h}$ at the nonpermissive temperature (Fig. 2C). Similarly, Rap1, which depends on TRF2 for its stability (Celli and de Lange 2005), persisted at $37^{\circ} \mathrm{C}$, as did TRF1 and POTla (Fig. 2C). The continued presence of TRF2ts suggested that TRF2 might reassociate with telomeres when cells are shifted back to $32^{\circ} \mathrm{C}$. Indeed, ChIP data indicated that upon a shift to $32^{\circ} \mathrm{C}$, the telomeric association of TRF2 and other shelterin components was improved (Fig. 2A,B). In addition, the TIF response in TRF2ts cells was attenuated when the cells were shifted back to $32^{\circ} \mathrm{C}$. Although a fraction of the cells continued to show signs of telo- 
A

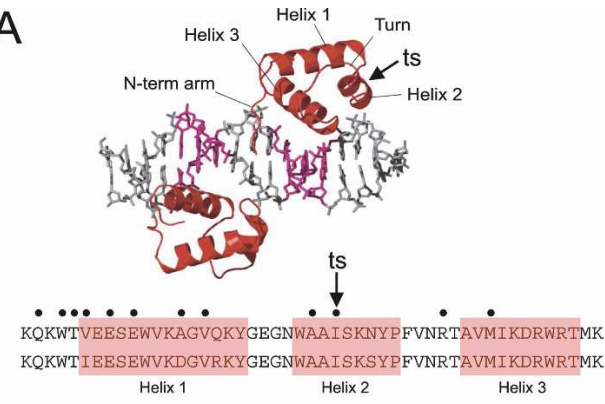

B

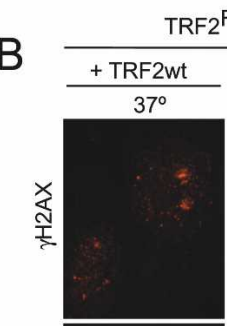

$\mathrm{TRF}^{\mathrm{F} /-} \mathrm{p} 53^{-/-} \mathrm{MEFs}+\mathrm{Cre}$
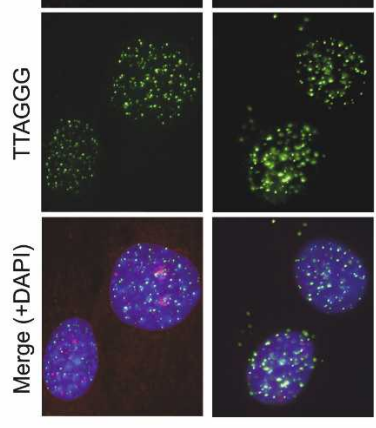

C

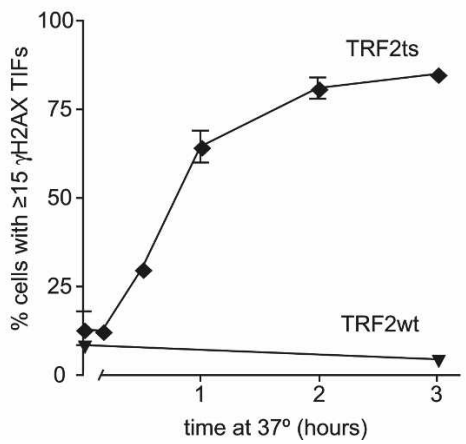

D

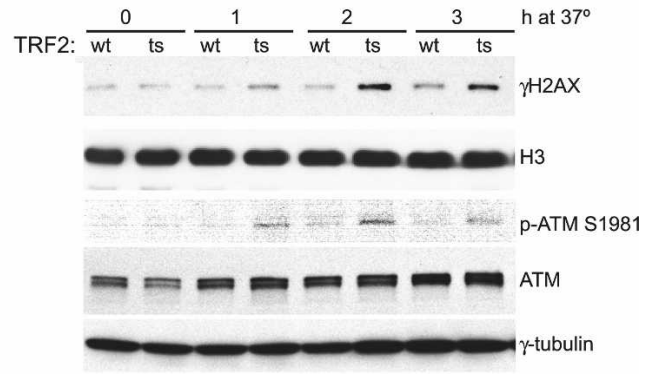

$\mathrm{E}$

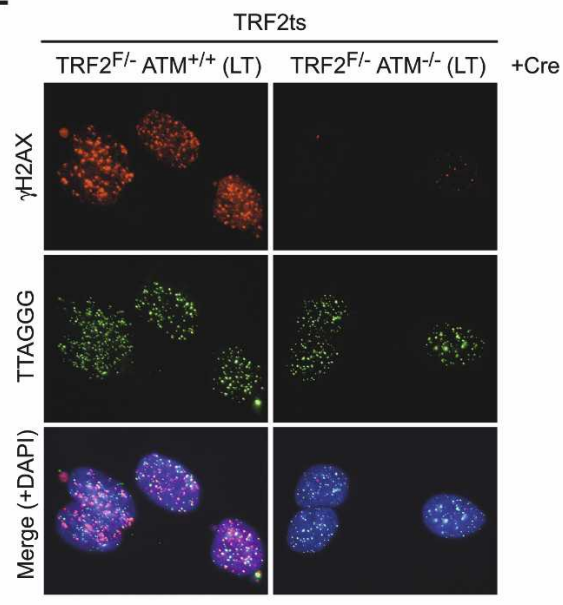

F

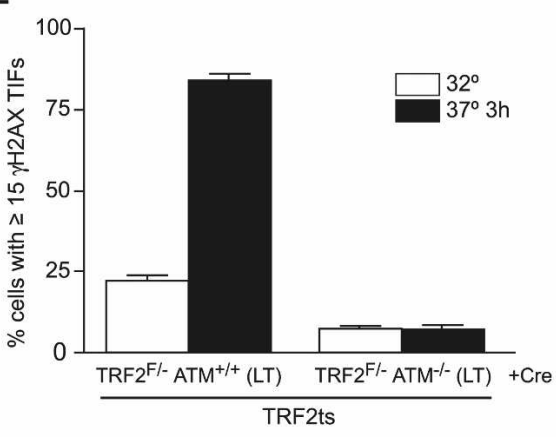

Figure 1. Generation of a ts allele of TRF2. (A) Schematic of the structure and sequence of the Myb/SANT domain of human and mouse TRF2 highlighting the position of the mutations tested for ts features (see Supplemental Table 1). (Top amino acid sequence) Human amino acids. (Bottom amino acid sequence) Mouse amino acids. The I473A ts mutation (I468A in mouse) is indicated with an arrow. The structure of the TRF2 Myb domains is taken from Rhodes (2005). (B) Temperature-dependent protection of telomeres by TRF2ts. TRF2ts and TRF2wt alleles were expressed in TRF2 $2^{\mathrm{F} /-} \mathrm{p} 53^{-/-}$MEFs followed by Cre treatment. Cells were incubated for $3 \mathrm{~h}$ at $32^{\circ} \mathrm{C}$ or $37^{\circ} \mathrm{C}$ and processed for IF-FISH $(\gamma \mathrm{H} 2 \mathrm{AX}$ [red] costained with telomeric TTAGGG-specific FISH probe [green]). The merged images include DAPI staining of DNA (blue). $(C)$ Time course of telomere deprotection at the nonpermissive temperature. TRF2ts and TRF2wt cells were incubated for the indicated time at $37^{\circ} \mathrm{C}$, processed for IF-FISH, and scored for 15 or more telomeric $\gamma \mathrm{H} 2 \mathrm{AX}$ foci in three independent experiments. Bars indicate standard deviations (SDs). (D) Detection of $\gamma \mathrm{H} 2 \mathrm{AX}$ and phosphorylated ATM-S1981. TRF2ts and wild-type TRF2 cells were incubated for the indicated times at $37^{\circ} \mathrm{C}$ and processed for Western blots. Histone H3, ATM, and $\gamma$-tubulin were used as a loading control. $(E)$ ATM dependency of the telomeric DNA damage signal. TRF2ts was expressed in ATM-proficient or -deficient TRF2 $2^{\mathrm{F} /-}$ cells immortalized with SV40-large T (LT) as indicated. TRF2 was deleted with Cre and the cells were processed as in $B$ after $3 \mathrm{~h}$ at $37^{\circ} \mathrm{C} .(F)$ Quantitation of the TIF response in $E$. Average TIF response values and SDs were derived from three independent experiments.

mere damage, the majority of the cells appeared to reestablish telomere protection within 2 h (Fig. 2E,F). Fur- thermore, the phosphorylation of $\mathrm{H} 2 \mathrm{AX}$ diminished strongly within $3 \mathrm{~h}$ of incubation at the permissive tem- 


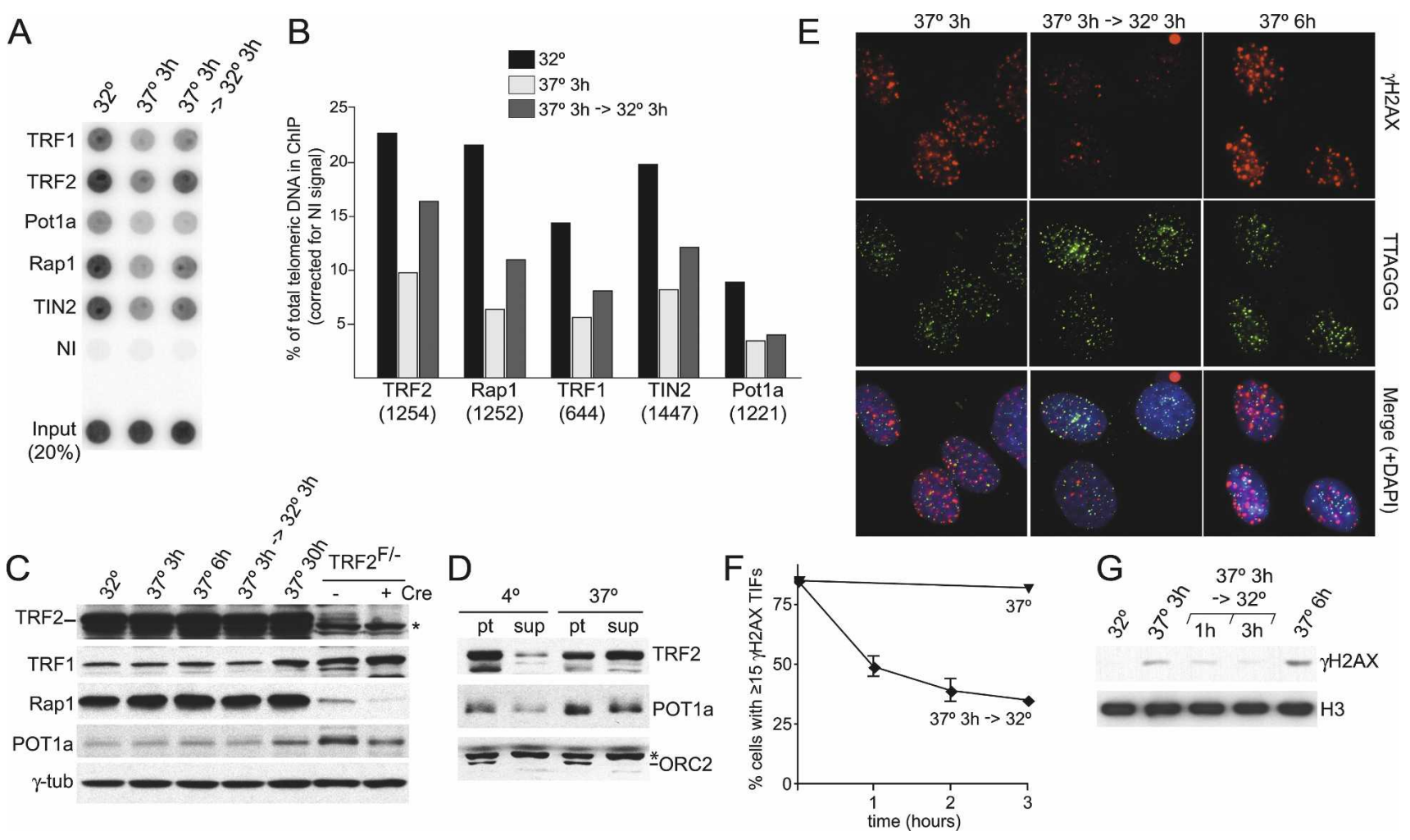

Figure 2. TRF2ts affords transient telomere deprotection through reversible telomere evacuation. $(A)$ ChIP with shelterin components in TRF2ts cells incubated for $3 \mathrm{~h}$ at $32^{\circ} \mathrm{C}$ or $37^{\circ} \mathrm{C}$, and for $3 \mathrm{~h}$ at $37^{\circ} \mathrm{C}$ followed by $3 \mathrm{~h}$ at $32^{\circ} \mathrm{C}$ incubation. Crude immune sera were used (serum number, indicated in $B$ ). (NI) Nonimmune serum. (B) Quantitative representation of the data in $A$. Percentage of telomeric DNA for each immunoprecipitation was calculated based on the signal relative to the corresponding total DNA signal. $(C)$ Immunoblot for TRF2 and other shelterin components during short or prolonged incubation at $37^{\circ} \mathrm{C}$. TRF2 $2^{\mathrm{F} /-} \mathrm{p} 53^{-/-} \mathrm{MEFs}$ with or without Cre treatment are shown as a control for the endogenous protein levels. $\left(^{\star}\right)$ Nonspecific signal. $(D)$ Release of TRF2ts and POT1a from nuclei incubated at $37^{\circ} \mathrm{C}$. Nuclei from TRF2ts cells were incubated for $30 \mathrm{~min}$ at $4^{\circ} \mathrm{C}$ or $37^{\circ} \mathrm{C}$ and subjected to centrifugation to separate released proteins (sup) from the nuclei (pt). ORC2 represents a chromatin-bound control. (E) Dissipation of $\gamma \mathrm{H} 2 \mathrm{AX}$ TIFs from TRF2ts cells upon shift to $32^{\circ} \mathrm{C}$. TRF2ts cells were incubated at $37^{\circ}$ and $32^{\circ} \mathrm{C}$ as indicated and processed to detect TIFs by IF-FISH as described in Figure 1B. $(F)$ Time course of reduction in TIF response after shift to $32^{\circ} \mathrm{C}$. TRF2ts cells were shifted for $3 \mathrm{~h}$ to $37^{\circ} \mathrm{C}$ and then incubated for the indicated time periods at either $37^{\circ} \mathrm{C}$ or $32^{\circ} \mathrm{C}$ and analyzed by IF-FISH for $\gamma \mathrm{H} 2 \mathrm{AX}$ TIFs. The graph shows average values of three experiments and SDs (bars). (G) Reversible induction of H2AX phosphorylation. TRF2ts cells were treated as indicated and analyzed for phosphorylation of H2AX by immunoblotting. Histone H3 serves as a loading control.

perature (Fig. 2G). In addition, brief (12 h or less) incubation at $37^{\circ} \mathrm{C}$ did not diminish the ability of the cells to form colonies, although longer incubation periods reduced cell viability (Supplemental Figure 1E). The dwindling of the TIFs was not due to DNA repair because they also disappeared from cells that lack DNA ligase IV, which is required for the NHEJ repair of dysfunctional telomeres (Supplemental Fig. 3A; Celli and de Lange 2005). We also checked that the decreased TIF frequency was not simply the result of incubation at a lower temperature by analyzing the frequency of TIF-positive cells in $\mathrm{TRF} 2^{\mathrm{F} /-} \mathrm{p} 53^{-/-}$MEFs that were shifted to $32^{\circ} \mathrm{C}$ after Cre-mediated deletion of TRF2 (Supplemental Fig. 3B). These cells showed unmitigated telomere deprotection at the lowered temperature, indicating that TIFs can be formed and/or persist at $32^{\circ} \mathrm{C}$. Finally, IR treatment elicited the expected DNA damage response in TRF2ts cells that were shifted back to $32^{\circ} \mathrm{C}$ (Supplemental Fig. 3C), indicating that their ability to respond to genome-wide DNA damage was intact. Therefore, we conclude that the I468A mutation in mouse TRF2 generates a protein whose ability to protect telomeres can be switched on and off in a temperature-dependent manner.

\section{Induction of telomere dysfunction in G0, G1, and $S / G 2$}

The rapid inactivation of TRF2ts allowed us to examine the cellular response to TRF2 loss in different stages of the cell cycle (Fig. 3A-C). In order to examine the TIF response in G0, TRF2ts MEFs were arrested by serum starvation for $4 \mathrm{~d}$, shifted to $37^{\circ} \mathrm{C}$, and examined for the presence of TIFs after $3 \mathrm{~h}$. Cells were synchronized in G1 by serum starvation followed by release into regular media and shifted to $37^{\circ} \mathrm{C}$ at $15 \mathrm{~h}$ after release into the cell cycle. Finally, S/G2 cell populations were generated using the serum starvation/release protocol, followed by aphidicolin treatment to synchronize cells at the beginning of $S$ phase. Removal of aphidicolin resulted in a population of cells that were in late $S$ phase or G2 $7 \mathrm{~h}$ 


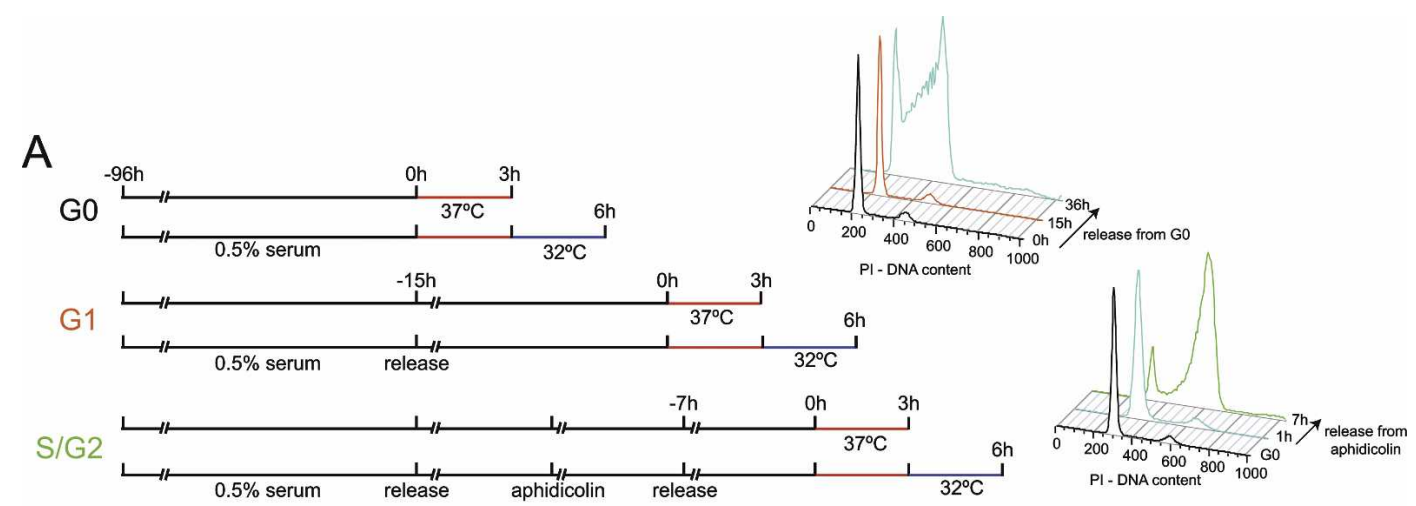

B

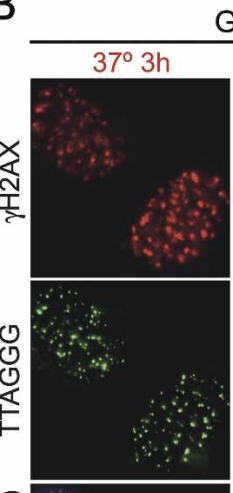

Go $37^{\circ} 3 h \rightarrow 32^{\circ} 3 h$

G1 $37^{\circ} 3 \mathrm{~h} \quad 37^{\circ} 3 \mathrm{~h}->32^{\circ} 3 \mathrm{~h}$

S/G2
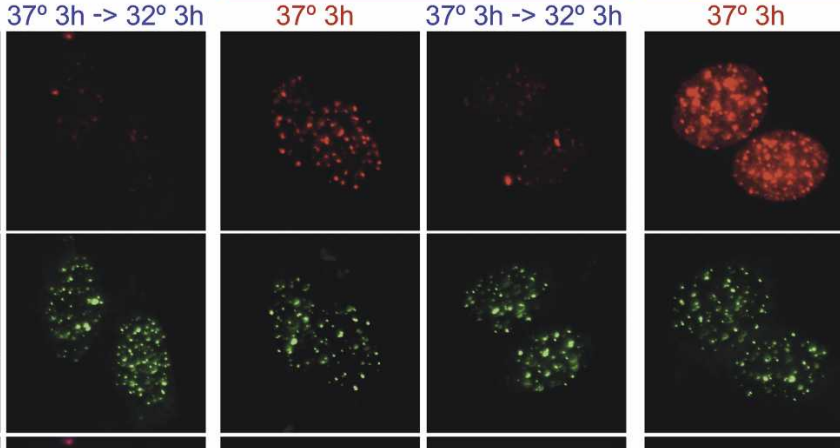

$37^{\circ} 3 \mathrm{~h} \rightarrow 32^{\circ} 3 \mathrm{~h}$
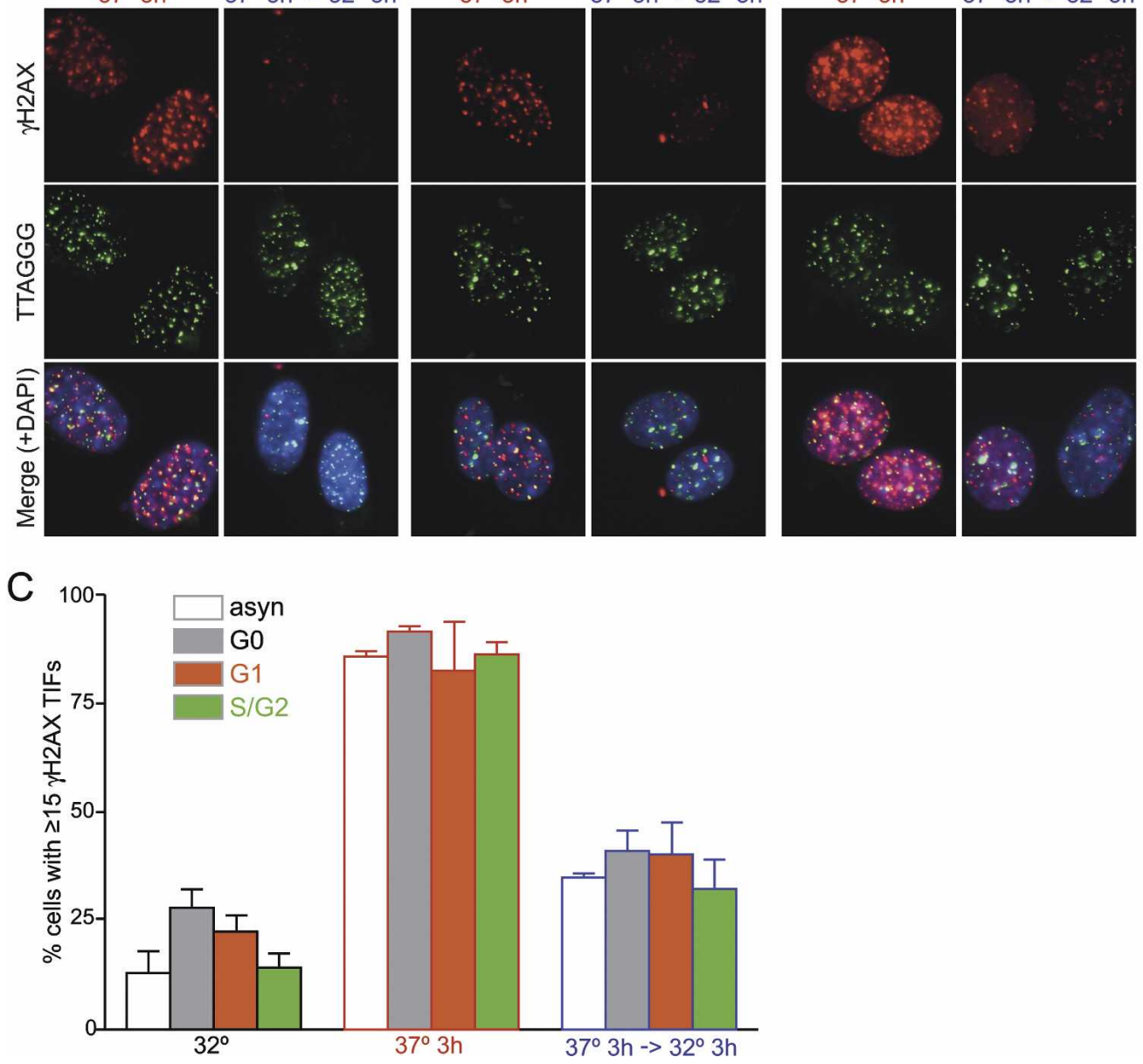

Figure 3. Loss and re-establishment of telomere protection in G0, G1, and S/G2. (A) Experimental time line for synchronization of TRF2ts cells in G0, G1, and S/G2. TRF2ts cells were arrested in G0 with low serum for $4 \mathrm{~d}$ (top) and released into normal medium, and cells in G1 were isolated after $15 \mathrm{~h}$ (middle, see FACS profile at $15 \mathrm{~h}$ ). (Bottom) For S/G2, G0 cells were released into normal medium followed by an aphidicolin block. At $7 \mathrm{~h}$ after release from aphidicolin, cells were in S/G2 (see FACS profile). (B) Reversible induction of $\gamma \mathrm{H} 2 \mathrm{AX}$ TIFs in G0, G1, and S/G2. TRF2ts cell in G0, G1, S/G2 were incubated for $3 \mathrm{~h}$ at $37^{\circ} \mathrm{C}$ with or without subsequent incubation for $3 \mathrm{~h}$ at $32^{\circ} \mathrm{C}$ and processed for $\gamma \mathrm{H} 2 \mathrm{AX}$ TIFs by IF-FISH as in Figure 1B. (C) Quantification of the TIF response. Cells shown in $B$ were scored for 15 or more telomeric $\gamma \mathrm{H} 2 \mathrm{AX}$ foci. Bars show average values of three independent experiments and SDs. (Asyn) Asynchronous culture.

later when they were shifted to $37^{\circ} \mathrm{C}$. The TIF response in these three synchronized populations of cells was very similar and not significantly different from the TIF re- sponse in asynchronous cells. Therefore, we conclude that telomeres can become deprotected in most interphase cells. 
Telomeres can regain their protected state in G0, G1, and $S / G 2$

We next asked whether the re-establishment of the protected state, as measured by the disappearance of TIFs, was cell cycle-dependent. Cells in G0, G1, or S/G2 were shifted to $37^{\circ} \mathrm{C}$, held at the nonpermissive temperature for $3 \mathrm{~h}$, and then moved back to $32^{\circ} \mathrm{C}$. The cell populations showed a significant reduction in TIF-positive cells at $32^{\circ} \mathrm{C}$ regardless of which cell cycle stage the cells were in (Fig. 3B,C). In all cases, there was a $50 \%$ reduction in this index for telomere deprotection, and the re-establishment of telomere protection was similar to that observed in asynchronous cells (Fig. 3C). Vector control cells treated with the same protocol showed persistent telomere deprotection, indicating that the ability of cells to regain telomere protection was dependent on TRF2 (Supplemental Fig. 3B). These results indicate that telomeres have the same ability to regain their protected state in G0, G1, and S/G2. Thus, the re-establishment of telomere protection does not require progression through DNA replication or mitosis.

\section{NHEJ of dysfunctional telomeres occurs primarily in G1}

In budding and fission yeast, NHEJ is largely limited to G1 most likely because CDK activity promotes resection of DNA ends in S and G2, thereby stimulating homologous recombination (HR) at the expense of NHEJ (Moore and Haber 1996; Godhino Ferreira and Promisel Cooper 2001; Aylon et al. 2004; Ira et al. 2004; Aylon and Kupiec 2005; Daley et al. 2005). For mammalian cells, it has been difficult to determine whether NHEJ is similarly confined to G1. Although NHEJ deficiency has a greater impact on the ability of cells to survive IR when radiated in G1 than in G2 (Stamato et al. 1988; Jeggo 1990; Rothkamm et al. 2003), this observation does not preclude that NHEJ is equally active in G1 and G2. Indeed, NHEJ of an ISceI-induced double-strand break (DSB) was found to be equally efficient in G1/S and G2/M (GuirouilhBarbat et al. 2007) and a role for NHEJ in (post-|replicative repair of DSBs was supported by observations in mice lacking Rad54 and DNA ligase IV (Mills et al. 2004). Furthermore, the NHEJ factor Ku70 can be detected at sites of laser-induced DNA damage in G1 and S/G2 (Kim et al. 2005), although quantitative ChIP suggested a much stronger association of Ku80 with an ISceI-induced DSB in G1 versus S/G2 (Rodrigue et al. 2006). Previous work has shown that NHEJ of dysfunctional telomeres can occur in G0, G1, and S/G2 (Bailey et al. 2001; Smogorzewska et al. 2002), but it is not known whether NHEJ of telomeres is more prominent in one of these cell cycle stages. In order to gain further insight into the cell cycle aspects of the NHEJ pathway, we analyzed telomere fusions in the context of the TRF2ts mutant (Fig. 4).

As expected, telomere fusion was a prominent outcome of telomere deprotection through inactivation of the TRF2ts allele at $37^{\circ} \mathrm{C}$. Strikingly, while the TIF response was fast, occurring within hours, telomere fusions were slow to appear, gradually increasing over a period of $24 \mathrm{~h}$ (Fig. 4A). Furthermore, when cells were shifted to the nonpermissive temperature for $4 \mathrm{~h}$ and then incubated at $32^{\circ} \mathrm{C}$, metaphase spreads harvested in the first 4-6 h after TRF2 inactivation did not show evidence of telomere fusions. Telomere fusions were first detected after $12 \mathrm{~h}$ and rose to peak levels at $18-24 \mathrm{~h}$ after the temperature shift (Fig. 4B).

The delayed wave of telomere fusions could be explained if NHEJ occurred primarily in G1. To test this possibility further, cells were synchronized in G0 by serum starvation and released into media containing BrdU so that their progression through G1 into $S$ phase could be followed based on BrdU incorporation. The cells were shifted for 4 -h time periods to $37^{\circ} \mathrm{C}$ either in $\mathrm{G} 1$ or in $\mathrm{S} / \mathrm{G} 2$, and their cell cycle stage was verified by FACS analysis (data not shown) and level of BrdU incorporation (Fig. 4C). Whereas telomere fusions were infrequent in the cells that had experienced $37^{\circ} \mathrm{C}$ during or after DNA replication, they were readily observed in cells treated at $37^{\circ} \mathrm{C}$ in G1 (Fig. 4C,D). Telomere fusions were also infrequent when cells were released from an aphidicolin block, allowed to progress into S/G2, and then incubated at $37^{\circ} \mathrm{C}$ (Fig. 4D). In this setting, the formation of sister telomere fusions was also monitored, since such fusions might be prominent after DNA replication. Sister telomere fusions were infrequent even when TRF2 was inactivated in S/G2 (Fig. 4D).

We further queried the NHEJ-mediated processing of dysfunctional telomeres by direct analysis of telomeric DNA. Telomere fusions can be detected in isolated telomeric DNA based on the loss of the telomeric 3' overhang and the appearance of higher-molecular-weight fragments. Both aspects of telomere fusion were evident in G0-arrested cells when they were incubated at the nonpermissive temperature (Fig. 4E), indicating that NHEJ was occurring in G0 and did not require progression through $\mathrm{S}$ phase. As expected, the extent of telomere processing was greater in the G0 cells than in the asynchronous population, which contains a large fraction of cells in S/G2/M (Fig. 4E).

Since the data suggested that NHEJ of telomeres is more prevalent in G1 than in S/G2, we asked whether this difference was a consequence of the lower CDK activity in G1. In order to lower the CDK activity in S/G2, synchronized TRF2ts cells were treated with the CDK inhibitor roscovitine during the 4-h period of incubation at $37^{\circ} \mathrm{C}$. This treatment resulted in a significant induction of sister telomere fusions (8\% of chromosomes) but not chromosome-type fusions. The sister telomere fusions were diminished in cells lacking DNA ligase IV, indicating that most were the result of NHEJ. Thus, NHEJ can act on telomeres after their replication, but this process is inhibited by a CDK-dependent pathway.

\section{Discussion}

Mammalian cells use shelterin to distinguish natural chromosome ends from sites of DNA damage (de Lange 2005). When shelterin is inactivated, the resulting dysfunctional telomeres activate the canonical DNA dam- 
A
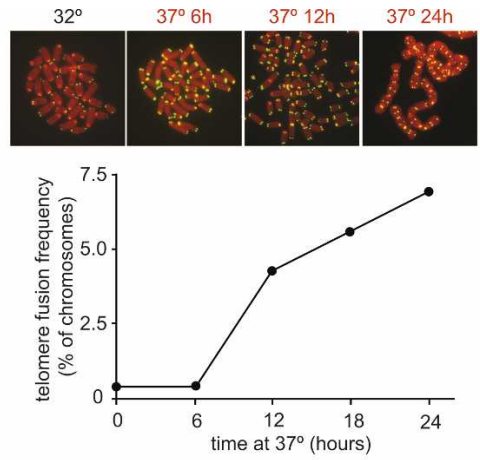

C

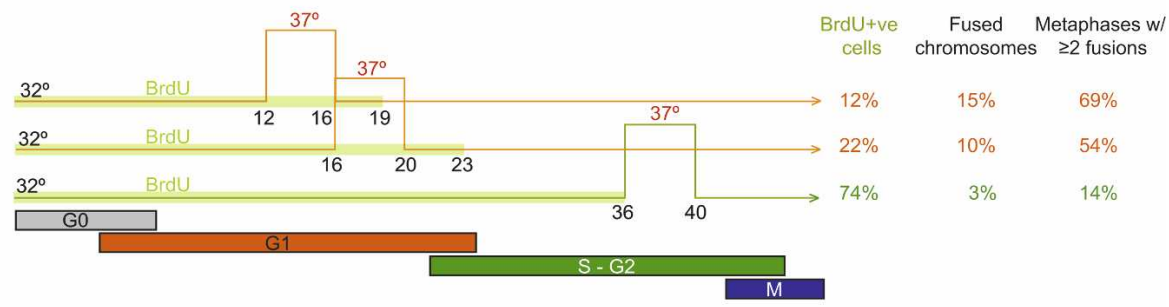

D

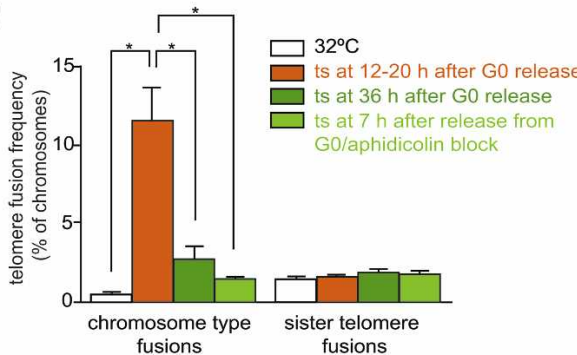

F

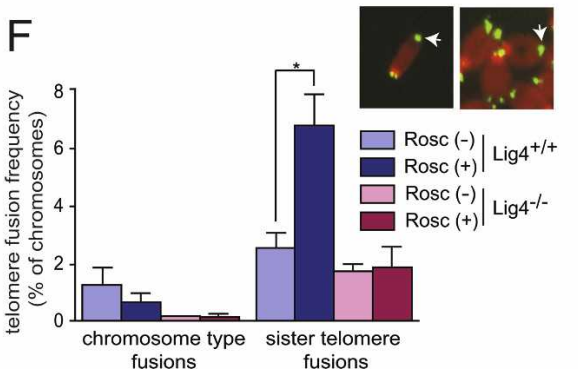

B
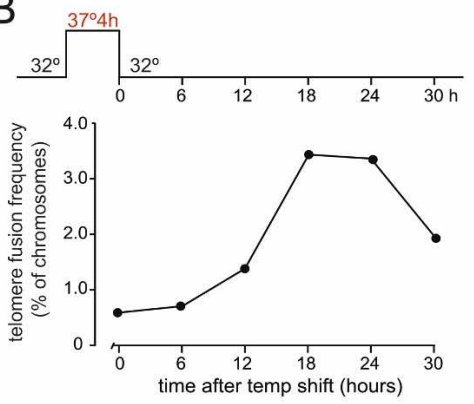
have generated interest in telomere dysfunction as a tool to understand the regulation of DNA damage signaling and repair. An advantage of using dysfunctional telomeres is that the molecular and cytological events can be monitored at the relevant sites. However, the slow time frame of shelterin inactivation using RNAi, dominantnegative alleles, and Cre-mediated deletion is a major disadvantage of this system. In addition, the resulting telomere dysfunction is not readily reversible. The ts allele of TRF2 described here overcomes these drawbacks.

The ts mutation in TRF2 changes a single amino acid in helix 2 of the Myb/SANT DNA-binding domain and results in a protein with diminished telomere-binding activity at $37^{\circ} \mathrm{C}$. TRF2ts affords telomere protection at $32^{\circ} \mathrm{C}$ but is released from telomeres when shifted to $37^{\circ} \mathrm{C}$. The resulting deprotected telomeres become processed as sites of DNA damage, rapidly activating the DNA damage signaling cascade and leading to NHEJmediated repair reactions. Remarkably, the TRF2ts allele is stable at the nonpermissive temperature and its inactivation is reversible: TRF2ts is able to rebind and protect telomeres upon a shift back to the permissive temperature. Due to these unique features, TRF2ts affords controlled deprotection of telomeres for desired time periods. These features compare favorably with other inducible systems (e.g., estrogen receptor [ER] fusions, inducible promoters, and FKBP degrons), which are either slower or not readily reversible.

The use of TRF2ts revealed the outcome of telomere dysfunction imposed at different stages of the cell cycle. The results indicate that telomere deprotection, as measured by the formation of TIFs, can be induced equally in G0, G1, and S/G2. Furthermore, such dysfunctional telomeres can regain their protected state in all stages of interphase upon incubation at the permissive temperature. Re-establishment of the protected state, as measured by the disappearance of TIFs and dampening of the DNA damage signal, is rapid, taking $<3 \mathrm{~h}$, and does not involve repair of the telomeres by NHEJ. Thus, the components needed to establish telomere protection in this context must be available in G0, G1, and S/G2 cells.

Whereas the loss and regain of telomere protection was not affected by cell cycle stage, the repair of deprotected telomeres by NHEJ was. NHEJ was significantly more prominent in G1 than in S/G2. In cell synchronization experiments, telomere fusions were five times more frequent when the telomeres had been uncapped in G1. The lower frequency of telomere fusions in S/G2 is due, in part, to the higher CDK activity in this phase of the cell cycle. Our results are consistent with findings in budding and fission yeast, where NHEJ repair of DSBs and uncapped telomeres is largely limited to G1 (Moore and Haber 1996; Godhino Ferreira and Promisel Cooper 2001; Aylon et al. 2004; Ira et al. 2004; Aylon and Kupiec 2005; Daley et al. 2005). Our findings are not in line with a previous demonstration that NHEJ of an induced DSB is equally efficient in cells arrested for $>15 \mathrm{~h}$ in G1/S and G2/M with mimosine and nocodazole, respectively (Guirouilh-Barbat et al. 2007). There are many explanations for this discrepancy, one being that our study ana- lyzed cells progressing through a normal cell cycle rather than being arrested.

Our results also inform on the rate of NHEJ of deprotected telomeres. Under conditions where most telomeres are associated with DNA damage factors for a 4- to 7-h time period, only $10 \%-15 \%$ of the telomeres become joined. This rate of fusion is slow compared with the rate of DSB repair in cells treated with IR or other genotoxic agents. In contrast, the majority of IR-induced DSBs are repaired in $<2 \mathrm{~h}$ and most of this repair is thought to involve NHEJ (Lobrich et al. 1995). One reason why repair of telomeres may be slow compared with the repair of random DSBs is that the distance between the DNA ends that will become joined. It was shown recently that the two ends created by a chromosome-internal DSB remain in close proximity (Soutoglou et al. 2007), presumably facilitating their joining. In contrast, most deprotected telomeres will be at a considerable distance from a potential fusion partner. Due to the slower time frame, telomere deprotection using the TRF2ts mutant may therefore provide a better setting to study the individual steps of NHEJ.

By mutating only 12 positions in the Myb/SANT domain of TRF2, we uncovered the strong ts allele used in these studies as well as three weaker ts alleles. This indicates that the Myb/SANT domain, in particular helices 1 and 2, are good targets for generating ts mutations. The Myb/SANT motif is a frequently used fold that serves as a DNA recognition module in a large array of different transcription factors. Given the small number $(<25)$ of helix $1 / 2$ residues to be queried, generating ts mutants in Myb/SANT transcription factors may be less daunting than anticipated previously.

\section{Materials and methods}

Mutagenesis of TRF2

Mutagenesis was carried out using QuickChange Site-Directed Mutagenesis Kit (Stratagene) according to the manufacturer's instructions. The template used was a pcDNA-based TRF2 (human or mouse) construct lacking the basic domain of TRF2, which, due to its high GC content, interferes with efficient PCR. Mutated TRF2 $\triangle \mathrm{B}$ versions were cut with BamHI and EcoRI and inserted into the Gateway pENTR acceptor plasmid containing the basic domain of human or mouse TRF2. All constructs were sequenced, and mutated TRF2s were transferred into a Gateway-modified pWzl-myc destination vector using clonase (Invitrogen).

Generation of TRF2ts and TRF2wt cells

$\mathrm{TRF}^{\mathrm{F} /}{ }^{-} \mathrm{p}^{-1 /-}$ and $\mathrm{TRF} 2^{\mathrm{F} /}{ }^{-} \mathrm{p} 53^{-/-} \mathrm{Lig} 4^{-/-}$MEFs were described previously (Celli and de Lange 2005). TRF2 mutant alleles were expressed from the retroviral pWzl vector followed by hygromycin selection at $37^{\circ} \mathrm{C}$. Cells were moved to $32^{\circ} \mathrm{C}$, and infected with H\&R Cre retrovirus to remove the floxed TRF2 allele. From this point on, cells were maintained at $32^{\circ} \mathrm{C}$.

\section{TIF assay}

IF-FISH to detect TIFs was performed as described previously (Dimitrova and de Lange 2006) using primary antibody against $\gamma \mathrm{H} 2 \mathrm{AX}$ (mouse monoclonal, Upstate Biotechnology), 53BP1 (100-304, Novus Biologicals), and secondary antibody raised 
against mouse and rabbit labeled with Rhodamine Red-X (RRX, Jackson). Briefly, cells grown on coverslips were fixed for $15 \mathrm{~min}$ in $2 \%$ paraformaldehyde at room temperature, followed by 15 min in $100 \%$ methanol at $-20^{\circ} \mathrm{C}$. After rehydration in PBS for 5 min, cells were incubated for $30 \mathrm{~min}$ in blocking solution (1 $\mathrm{mg} / \mathrm{mL}$ BSA, $3 \%$ goat serum, $0.1 \%$ Triton X-100, 1 mM EDTA in PBS). Next, the cells were incubated with primary antibodies in blocking solution for $1 \mathrm{~h}$ at temperature, washed three times in PBS, incubated with secondary antibodies in blocking solution for $30 \mathrm{~min}$, and washed again three times in PBS. At this point, coverslips were fixed with $2 \%$ paraformaldehyde for 15 min at room temperature; washed again twice in PBS; dehydrated consecutively in $70 \%, 95 \%$, and $100 \%$ ethanol, $5 \mathrm{~min}$ each; and allowed to dry completely. Hybridizing solution $170 \%$ formamide, $1 \mathrm{mg} / \mathrm{mL}$ blocking reagent [Roche], $10 \mathrm{mM}$ Tris$\mathrm{HCl}$ at $\mathrm{pH} 7.2$, containing PNA probe Tamra-(TTAGGG) ${ }_{3}$ [Applied Biosystems]) was added to each coverslip, and the cells were denatured by heating for $10 \mathrm{~min}$ at $80^{\circ} \mathrm{C}$ on a heat block. After $2 \mathrm{~h}$ incubation at room temperature in the dark, cells were washed twice with wash solution $(70 \%$ formamide, $10 \mathrm{mM}$ Tris- $\mathrm{HCl}$ at $\mathrm{pH} 7.2)$ and twice in PBS. DNA was counterstained with 4,6-diamidino-2-phenylindole (DAPI) and slides were mounted in $90 \%$ glycerol $/ 10 \%$ PBS containing $1 \mu \mathrm{g} / \mathrm{mL}$ p-phenylene diamine (Sigma). Digital images were captured with a Zeiss Axioplan II microscope with a Hamamatsu C4742-95 camera using Improvision OpenLab software.

\section{Immunoblotting}

Cells were lysed in $2 \times$ Laemmli buffer $(100 \mathrm{mM}$ Tris- $\mathrm{HCl}$ at $\mathrm{pH}$ 6.8, 200 mM DTT, 3\% SDS, $20 \%$ glycerol, $0.05 \%$ bromophenol blue) at $10^{4}$ cells per microliter, denatured for $5 \mathrm{~min}$ at $100^{\circ} \mathrm{C}$, and sheared with an insulin needle before loading the equivalent of $1 \times 10^{5}$ cells per lane. After immunoblotting, membranes were blocked in PBS or TBS with $5 \%$ milk and $0.1 \%$ Tween 20 , and incubated with the following primary antibodies in $5 \%$ milk and $0.1 \%$ Tween 20 : affinity-purified rabbit antibody raised against mTRF2, \#1254; mRAP1, \#1252; mTRF1 (A. Sfeir and T. de Lange, unpubl.); $\gamma$-tubulin (clone GTU 488, Sigma); $\gamma \mathrm{H} 2 \mathrm{AX}$ (mouse monoclonal, Upstate Biotechnology); phosphorylated ATM S-1981 (mouse monoclonal, Cell Signaling Technology); phosphorylated Chk1 S-317 (rabbit monoclonal, Cell Signaling Technology); Chk2 (mouse monoclonal, BD); myc (clone 9E10, Calbiochem). Immunoblots for POT1a and POT1b were performed using the renaturation protocol described previously (Loayza and de Lange 2003; Hockmeyer et al. 2006) with affinity-purified antibody raised against POT1a \#1221 and POT1b \#1223. Blots were developed with enhanced chemiluminescence (Amersham).

\section{ChIP}

ChIPs were performed as described previously (Loayza and de Lange 2003; Ye et al. 2004) with some modification. Cells were cross-linked on the dish with $2 \%$ paraformaldehyde for $30 \mathrm{~min}$ at room temperature followed by chelating with glycine, washes with cold PBS, and treatment with $20 \%$ trypsin followed by inactivation with serum. Cells were scraped, washed twice in cold PBS, resuspended into cell lysis buffer $15 \mathrm{mM}$ PIPES at $\mathrm{pH}$ 8.0, $85 \mathrm{mM} \mathrm{KCl}, 0.5 \%$ NP-40, $1 \mathrm{mM}$ PMSF, Complete protease inhibitor cocktail [Roche]) at $1 \times 10^{7}$ cells per milliliter, incubated for $10 \mathrm{~min}$ on ice, and centrifuged at $5000 \mathrm{rpm}$ for $10 \mathrm{~min}$. Pellets were resuspended in ChIP immunoprecipitation buffer (20 mM Tris- $\mathrm{HCl}$ at $\mathrm{pH} 8.0,150 \mathrm{mM} \mathrm{NaCl}, 2 \mathrm{mM}$ EDTA, $1 \%$ Triton X-100, $0.1 \%$ SDS, $1 \mathrm{mM}$ PMSF, Complete protease inhibitor) and then sonicated. Lysates were centrifuged at 13,400 $\mathrm{rpm}$ for $10 \mathrm{~min}$ and the supernatants were used in immunopre- cipitations with affinity-purified rabbit antibody raised against mTRF1 \#644, mTRF2 \#1254, mRap1 \#1252, mPOT1a \#1221, and mTIN2 \#1447 (J. Donigian and T. de Lange, unpubl.). Precipitated DNA was washed, extracted, blotted, and hybridized with TTAGGG repeat probe to detect telomeric DNA.

\section{In vitro release of TRF2 from nuclei}

Cells were washed in cold PBS, resuspended in solution A (10 $\mathrm{mM}$ Hepes at $\mathrm{pH} 7.9,10 \mathrm{mM} \mathrm{KCl}, 1.5 \mathrm{mM} \mathrm{MgCl}_{2}, 0.34 \mathrm{M}$ sucrose, $10 \%$ glycerol, $0.1 \%$ Triton X-100, $1 \mathrm{mM} \mathrm{DTT,} 1 \mathrm{mM}$ PMSF, Complete protease inhibitors), incubated on ice for 10 min, and centrifuged at $1300 \mathrm{~g}$ for $4 \mathrm{~min}$. Pellets were washed with solution A, resuspended in solution $B(3 \mathrm{mM}$ EDTA, 0.2 mM EGTA, 1 mM DTT, 1 mM PMSF, Complete protease inhibitor), incubated on ice for $30 \mathrm{~min}$, and centrifuged at $1700 \mathrm{~g}$ for 4 min. Pellets were washed with solution $B$ twice and pellets were resuspended in a small volume of solution $\mathrm{B}$, incubated for 30 min at $4^{\circ} \mathrm{C}$ or $37^{\circ} \mathrm{C}$, and centrifuged. Supernatants and pellets were collected and used for Western blot analysis.

\section{Cell synchronization}

G0 synchronization was done by serum starvation. Cells were plated at $1 \times 10^{6}$ cells per $10-\mathrm{cm}$ dish or $1.5 \times 10^{7}$ to $2.0 \times 10^{7}$ cells per $15-\mathrm{cm}$ dish in medium supplemented with $0.5 \%$ serum and incubated for $96 \mathrm{~h}$. Cells were harvested and plated at $1 \times 10^{6}$ cells per 10 -cm dish in medium supplemented with $10 \%$ serum to allow them to proceed to the G1 cell cycle phase. Aphidicolin was added $12 \mathrm{~h}$ after G0 release and cells were incubated for $12-15 \mathrm{~h}$ to synchronize in early $\mathrm{S}$ phase. Cells were then washed with PBS three times and incubated in normal medium to proceed to the G2 cell cycle phase.

\section{Telomere FISH on metaphase spreads}

Cells were harvested at the indicated time points and fixed as described previously (van Steensel et al. 1998). Metaphase spreads were aged overnight and peptide nucleic acid (PNA) FISH was performed (Lansdorp 1996). Briefly, slides were washed in PBS once and dehydrated by consecutive 5-min incubations in $70 \%, 95 \%$, and $100 \%$ ethanol. After air-drying, hybridizing solution (as in IF-FISH) containing FITC-OO$(\text { CCCTAA })_{3}$ PNA probe (Applied Biosystems) was added and spreads were denatured by heating for $3 \mathrm{~min}$ at $80^{\circ} \mathrm{C}$ on a heat block. Spreads were hybridized in the dark for $2 \mathrm{~h}$ at room temperature. Two 15 -min washes were performed in $70 \%$ formamide/10 mM Tris-HCl (pH 7.0)/0.1\% BSA, followed by three washes in $0.1 \mathrm{M}$ Tris- $\mathrm{HCl}(\mathrm{pH} 7.0) / 0.15 \mathrm{M} \mathrm{NaCl} / 0.08 \%$ Tween20 with DAPI added to the second wash to counterstain the chromosomal DNA.

Pulsed-field gel electrophoresis and in-gel detection of telomeric DNA

The detection and quantitation of single-stranded (G-overhang) telomeric DNA and double-stranded telomeric DNA was performed as described previously (Celli and de Lange 2005; Lazzerini Denchi and de Lange 2007) using in-gel hybridization of a [CCCTAA]4 oligonucleotide probe to native and denatured DNA. The G-overhang signals (obtained on native DNA) were normalized to the total telomeric DNA signals (obtained on the same gel after $\mathrm{NaOH}$ denaturation of the DNA) in the same lane and normalized values were compared between samples.

\section{Acknowledgments}

We are extremely grateful to Daniela Rhodes for her guidance on which positions in the Myb/SANT domain to target for mutagenesis. Kristina Hoke is thanked for the TRF2 plasmids used 
for mutagenesis and Jill Donigian and Agnel Sfeir are thanked for providing antibodies. A.K. was supported by post-doctoral fellowships from the Uehara Memorial Foundation and the $\mathrm{Hu}-$ man Frontier Science Program. This work was supported by a NIH Directors Pioneer Award to T.d.L. (OD000379) and a grant from the NIH (GM049046).

\section{References}

Aylon, Y. and Kupiec, M. 2005. Cell cycle-dependent regulation of double-strand break repair: A role for the CDK. Cell Cycle 4: 259-261.

Aylon, Y., Liefshitz, B., and Kupiec, M. 2004. The CDK regulates repair of double-strand breaks by homologous recombination during the cell cycle. EMBO J. 23: 4868-4875.

Bailey, S.M., Cornforth, M.N., Kurimasa, A., Chen, D.J., and Goodwin, E.H. 2001. Strand-specific postreplicative processing of mammalian telomeres. Science 293: 2462-2465.

Bilaud, T., Brun, C., Ancelin, K., Koering, C.E., Laroche, T., and Gilson, E. 1997. Telomeric localization of TRF2, a novel human telobox protein. Nat. Genet. 17: 236-239.

Broccoli, D., Smogorzewska, A., Chong, L., and de Lange, T. 1997. Human telomeres contain two distinct Myb-related proteins, TRF1 and TRF2. Nat. Genet. 17: 231-235.

Celli, G. and de Lange, T. 2005. DNA processing not required for ATM-mediated telomere damage response after TRF2 deletion. Nat. Cell Biol. 7: 712-718.

Chong, L., van Steensel, B., Broccoli, D., Erdjument-Bromage, H., Hanish, J., Tempst, P., and de Lange, T. 1995. A human telomeric protein. Science 270: 1663-1667.

Court, R., Chapman, L., Fairall, L., and Rhodes, D. 2005. How the human telomeric proteins TRF1 and TRF2 recognize telomeric DNA: A view from high-resolution crystal structures. EMBO Rep. 6: 39-45.

Daley, J.M., Palmbos, P.L., Wu, D., and Wilson, T.E. 2005. Nonhomologous end joining in yeast. Annu. Rev. Genet. 39: 431451.

de Lange, T. 2005. Shelterin: The protein complex that shapes and safeguards human telomeres. Genes \& Dev. 19: 2100-2110.

Dimitrova, N. and de Lange, T. 2006. MDC1 accelerates nonhomologous end-joining of dysfunctional telomeres. Genes \& Dev. 20: 3238-3243.

Godhino Ferreira, M. and Promisel Cooper, J. 2001. The fission yeast Tazl protein protects chromosomes from Ku-dependent end-to-end fusions. Mol. Cell 7: 55-63.

Guirouilh-Barbat, J., Huck, S., and Lopez, B.S. 2007. S-phase progression stimulates both the mutagenic KU-independent pathway and mutagenic processing of KU-dependent intermediates, for nonhomologous end joining. Oncogene 27: $1726-1736$

Hanaoka, S., Nagadoi, A., and Nishimura, Y. 2005. Comparison between TRF2 and TRF1 of their telomeric DNA-bound structures and DNA-binding activities. Protein Sci. 14: 119-130.

Hockemeyer, D., Daniels, J.P., Takai, H., and de Lange, T. 2006. Recent expansion of the telomeric complex in rodents: Two distinct POT1 proteins protect mouse telomeres. Cell 126: 63-77.

Ira, G., Pellicioli, A., Balijia, A., Wang, X., Fiorani, S., Carotenuto, W., Liberi, G., Bressan, D., Wan, L., Hollingsworth, N.M., et al. 2004. DNA end resection, homologous recombination and DNA damage checkpoint activation require CDK1. Nature 431: 1011-1017.

Jeggo, P.A. 1990. Studies on mammalian mutants defective in rejoining double-strand breaks in DNA. Mutat. Res. 239: 1-16.

Kim, J.S., Krasieva, T.B., Kurumizaka, H., Chen, D.J., Taylor, A.M., and Yokomori, K. 2005. Independent and sequential recruitment of NHEJ and HR factors to DNA damage sites in mammalian cells. J. Cell Biol. 170: 341-347.

Kurtz, S. and Shore, D. 1991. RAP1 protein activates and silences transcription of mating-type genes in yeast. Genes \& Dev. 5: 616-628.

Lansdorp, P.M., Verwoerd, N.P., van de Rijke, F.M., Dragowska, V., Little, M.T., Dirks, R.W., Raap, A.K., and Tanke, H.J 1996. Heterogeneity in telomere length of human chromosomes. Hum. Mol. Genet. 5: 685-691.

Lazzerini Denchi, E. and de Lange, T. 2007. Protection of telomeres through independent control of ATM and ATR by TRF2 and POT1. Nature 448: 1068-1071.

Li, R.P., Duterque-Coquillaud, M., Lagrou, C., Debuire, B., Graf, T., Stehelin, D., and Leprince, D. 1989. A single amino-acid substitution in the DNA-binding domain of the myb oncogene confers a thermolabile phenotype to E26-transformed myeloid cells. Oncogene Res. 5: 137-141.

Loayza, D. and de Lange, T. 2003. POT1 as a terminal transducer of TRF1 telomere length control. Nature 424: 1013-1018.

Lobrich, M., Rydberg, B., and Cooper, P.K. 1995. Repair of X-rayinduced DNA double-strand breaks in specific Not I restriction fragments in human fibroblasts: Joining of correct and incorrect ends. Proc. Natl. Acad. Sci. 92: 12050-12054.

Lustig, A.J., Kurtz, S., and Shore, D. 1990. Involvement of the silencer and UAS binding protein RAP1 in regulation of telomere length. Science 250: 549-553.

Mills, K.D., Ferguson, D.O., Essers, J., Eckersdorff, M., Kanaar, R., and Alt, F.W. 2004. Rad54 and DNA ligase IV cooperate to maintain mammalian chromatid stability. Genes \& Dev. 18: $1283-1292$.

Moore, J.K. and Haber, J.E. 1996. Cell cycle and genetic requirements of two pathways of nonhomologous end-joining repair of double-strand breaks in Saccharomyces cerevisiae. Mol. Cell. Biol. 16: 2164-2173.

Rhodes, D. 2005. The structural biology of telomeres. In Telomeres (eds. de Lange, T. et al.) pp. 317-344. Cold Spring Harbor Laboratory Press, Cold Spring Harbor, NY.

Rodrigue, A., Lafrance, M., Gauthier, M.C., McDonald, D., Hendzel, M., West, S.C., Jasin, M., and Masson, J.Y. 2006. Interplay between human DNA repair proteins at a unique double-strand break in vivo. EMBO J. 25: 222-231.

Rothkamm, K., Kruger, I., Thompson, L.H., and Lobrich, M. 2003. Pathways of DNA double-strand break repair during the mammalian cell cycle. Mol. Cell. Biol. 23: 5706-5715.

Smogorzewska, A., Karlseder, J., Holtgreve-Grez, H., Jauch, A., and de Lange, T. 2002. DNA ligase IV-dependent NHEJ of deprotected mammalian telomeres in G1 and G2. Curr. Biol. 12: $1635-1644$

Soutoglou, E., Dorn, J.F., Sengupta, K., Jasin, M., Nussenzweig, A., Ried, T., Danuser, G., and Misteli, T. 2007. Positional stability of single double-strand breaks in mammalian cells. Nat. Cell Biol. 9: 675-682.

Stamato, T.D., Dipatri, A., and Giaccia, A. 1988. Cell-cycle-dependent repair of potentially lethal damage in the XR-1 $\gamma$-ray-sensitive Chinese hamster ovary cell. Radiat. Res. 115: 325-333.

Takai, H., Smogorzewska, A., and de Lange, T. 2003. DNA damage foci at dysfunctional telomeres. Curr. Biol. 13: 1549-1556.

van Steensel, B., Smogorzewska, A., and de Lange, T. 1998. TRF2 protects human telomeres from end-to-end fusions. Cell 92: 401-413.

Ye, J.Z., Hockemeyer, D., Krutchinsky, A.N., Loayza, D., Hooper, S.M., Chait, B.T., and de Lange, T. 2004. POT1interacting protein PIP1: A telomere length regulator that recruits POT1 to the TIN2/TRF1 complex. Genes \& Dev. 18: $1649-1654$. 


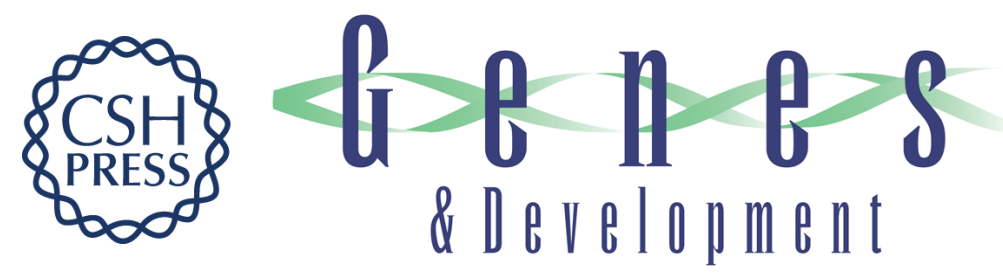

\section{Cell cycle control of telomere protection and NHEJ revealed by a ts mutation in the DNA-binding domain of TRF2}

Akimitsu Konishi and Titia de Lange

Genes Dev. 2008, 22:

Access the most recent version at doi:10.1101/gad.1634008

Supplemental http://genesdev.cshlp.org/content/suppl/2008/04/14/22.9.1221.DC1
Material

References This article cites 35 articles, 13 of which can be accessed free at: http://genesdev.cshlp.org/content/22/9/1221.full.html\#ref-list-1

License Freely available online through the Genes \& Development Open Access option.

Email Alerting Receive free email alerts when new articles cite this article - sign up in the box at the top Service right corner of the article or click here.

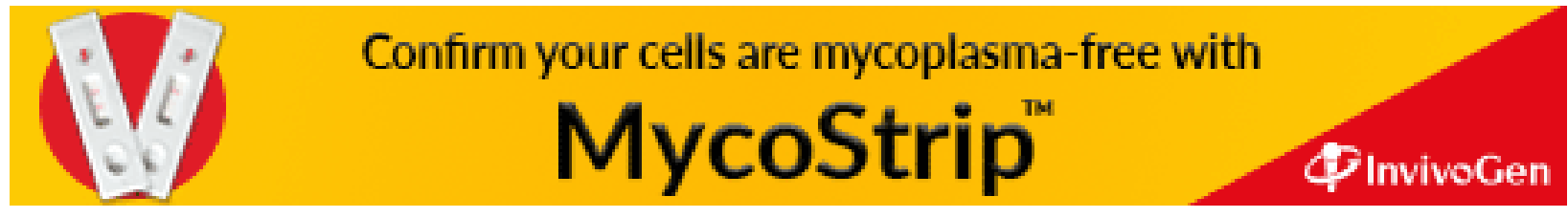

